\section{Workplace Diversity and Inclusion}

\section{Andrew R. Grissom}

Andrew R. Grissom, MS, is Associate Librarian, Catalyst Information Center, New York, New York.

Correspondence concerning this column should be addressed to Mark Shores; e-mail: shoresml@miamioh.edu.
It is usually assumed that the Alert Collector column author has some expertise on the subject covered. This is especially true this issue for author Andrew R. Grissom's column on workpace diversity and inclusion. Grissom is an information professional at a nonprofit devoted to these issues. You could say he "lives and breathes" this topic. The column has something for all libraries, whether you are seeking to expand your circulating collections or offer an in-house collection of resources to help your library create or maintain an inclusive workplace.—Editor

$\mathbf{T}$

he US Bureau of Labor Statistics estimates that ore than 38 million people will enter the labor force between 2016 and 2026. ${ }^{1}$ Over this decade, the composition of the labor force will become older and more racially and ethnically diverse. ${ }^{2}$ As these demographics shift, how will organizations treat individual differences, marginalized groups, and wide-ranging skills, and expertise? When these new workers enter their first jobs, will they experience inclusive cultures, in which everyone can bring their full selves to work and thrive?

Efforts to protect marginalized and minority groups from workplace discrimination go back decades: Title VII of the Civil Rights Act of 1964 established a federal law that prohibits employers from discriminating against employees because of race, color, religion, sex, and national origin. ${ }^{3}$ More than fifty years later, despite progress, women and minorities remain underrepresented across the top decision-making levels in workplaces across the United States. Women account for almost half (48.9 percent) of the overall labor force, ${ }^{4}$ but not even a quarter (20.2 percent) of board directors across Fortune 500 companies. ${ }^{5}$ The situation is even worse for people of color: minority women and men represent only 14.4 percent of board directors. ${ }^{6}$

Now more than ever, diversity and inclusion are critical topics in workplaces around the world. The \#MeToo and "Time's Up" movements are currently placing a spotlight on sexual harassment and abuse of power in many industries. Companies across the world are pursuing initiatives to combat biases and remove barriers that exclude underrepresented and marginalized groups from having a "seat at the table."

For libraries and the library profession, equality is critical to our professional identity and ethos. The American Library Association lists diversity as one of its eight key action areas and a fundamental value of the association. ${ }^{7}$ Information 
professionals are not only expected to support inclusive practices in the recruitment, hiring, and retention of diverse colleagues within the field but must also advocate for inclusion in the delivery of their day-to-day work, including how they approach customer service, collection development, programs, academic freedom, and diversity of thought. ${ }^{8}$

The following list assists in selecting works that raise awareness and prepare the next generation of professionals for some of the leading issues facing workplaces todayfrom the marginalization of women, racial/ethnic minority groups, people with disabilities, and other minority groups in the global workforce, to the current efforts of organizations to reduce exclusion and foster inclusion. This list also will support both the research needs of academic audiences and practitioners who encounter diversity-related issues in the course of their work (for example, resolving an instance of employment discrimination or developing a program to increase the representation of diverse groups within a workplace or industry). Finally, the resources below can facilitate internal efforts of a library staff or its parent organization in the recruitment, hiring, and retention of their own diverse workforce.

Workplace diversity and inclusion is a very broad topic that covers many themes (for example, inclusive cultures, leadership, discrimination, unconscious bias) and groups (for example, women, men, people of color, veterans, people with disabilities, LGBT professionals). This list is not exhaustive, and it is meant as a sampling of published resources. In addition to more traditional resources (books, journals, and magazines), the websites listed in the "Organizations" section offer additional research, programming, and facilitator expertise, which are helpful for organizations seeking to change cultural norms and open conversations on diversity issues.

\section{REFERENCE BOOKS}

Bendl, Regine, Inge Bleijenbergh, Elina Henttonen, and Albert J. Mills, eds. The Oxford Handbook of Diversity in Organizations. New York: Oxford University Press, 2015. ISBN: 9780199679805.

"What is diversity and what does it have to do with organizations?" This collection of academic research attempts to answer just that, providing a foundation of diversity management from the many multidisciplinary, intersectional, epistemological, and theoretical approaches to the field. The book's twenty-eight chapters are divided into six parts: theoretical pluralism, epistemological approaches, methodologies, diversity practices, intersectional approaches, and the future of the field. Bringing together prominent scholars from across the world, this handbook is a valuable addition to research collections. However, the highly theoretical nature of the book may be less accessible to non-scholarly audiences.
Gardenswartz, Lee, and Anita Rowe. Managing Diversity: A Complete Desk Reference and Planning Guide. Alexandria, VA: Society for Human Resource Management, 2010. ISBN: 9781586441562.

An ideal reference guide for senior leaders, supervisors, or anyone responsible for workforce diversity work, this book contains practical tools to implement diversity initiatives in any organization. Chock full of charts, assessments, activities, audits, and worksheets, Managing Diversity is an approachable "how-to" for creating a culture change and maximizing the efficiency of a diverse workforce. The third edition contains updated tips for managing global teams. Many of the training materials are included on the accompanying CD-ROM.

Kumra, Savita, Ruth Simpson, and Ronald J. Burke, eds. The Oxford Handbook of Gender in Organizations. New York: Oxford University Press, 2014. ISBN: 9780199658213.

This handbook offers a sampling of the broad range of research on contemporary issues relating to women's and men's experience at work. The introduction, written by the book's three editors, who are highly prolific in this field, provides a particularly useful overview of the major research areas and emerging topics in this space. The remaining twenty-four chapters are divided into four sections: "Theorizing Gender and Organizations," "Gender in Leadership and Management," "Gender and Careers," and "Masculinities in Organizations."

Roberson, Quinetta M., ed. The Oxford Handbook of Diversity and Work. Oxford Library of Psychology. New York: Oxford University Press, 2013. ISBN: 9780199736355.

As organizations become increasingly diverse, scholars across many disciplines continue to study the nature of this phenomenon, its meaning, consequences, and policy and practice implementations. This collection illuminates the breadth of this research from scholars across the globe, divided into eight parts to cover broad areas, including theories and conceptions of diversity, psychology, interactions and knowledge exchange, context, practices, and systems. The handbook ends with an overview of future directions for scholarly work in this space.

Scott, Craig R., and Laurie K. Lewis, eds. The International Encyclopedia of Organizational Communication. Hoboken, NJ: Wiley, 2017. ISBN: 9781118955604.

Awarded the 2017 Best Edited Book award by the Organizational Communication Division of the National Communication Association, this four-volume set is an authoritative source on the broad field of organizational communication. The volumes include several entries relating to workplace diversity, such as corporate social responsibility, disability, diversity, feminist approaches, gender and organizing, intergenerational communication in the workplace, queer approaches, race and organizing, and work-life balance. 


\section{THE ALERT COLLECTOR}

\section{BOOKS}

Brislin, Richard. Working with Cultural Differences: Dealing Effectively with Diversity in the Workplace. Contributions in Psychology Series. Westport, CT: Praeger, 2008. ISBN: 9780313352829.

Intercultural interactions are becoming an increasingly common feature of many industries. Richard Breslin argues that workers are not only unprepared for such interactions, but they might actually need to reexamine and correct some of the cultural norms and assumptions formed in childhood. Working with Cultural Differences parses through cultural differences from a psychological perspective, covering such topics as individualism, silence, gender differences, power, status, criticism, and social norms, among others. This work is essential reading for students entering a global and diverse workforce, as well as for researchers and diversity professionals.

Burke, Ronald J., and Astrid M. Richardsen. Women in Management Worldwide: Signs of Progress. New York: Routledge, 2017. ISBN: 9781472462718, hardcover; 9781315546742 , e-book.

The third edition in the Women in Management Worldwide series, Signs of Progress examines the state of women in the workforce, management and leadership, company initiatives, and legislation furthering women's advancement around the world. The editors organize the book to provide country profiles on these topics, providing statistical data in order to enable country-by-country comparison. The newest edition covers twenty countries (one more than the second edition) and includes a new regional focus on the Middle East. This is a valuable resource for those seeking a broad coverage of data on women's progress across the world. An ebook version is also available.

Davidson, Martin N. The End of Diversity as We Know It: Why Diversity Efforts Fail and How Leveraging Difference Can Succeed. San Franicsco: Berrett-Koehler, 2011. ISBN: 9781605093437.

Most diversity programs are flawed and not effectively aligned with strategic business needs, according to Martin N. Davidson, a business consultant and professor, associate dean, and chief diversity officer at the University of Virginia's Darden School of Business. Davidson's "Leveraging Difference" approach conceptualizes diversity in a new way: instead of an initiative handed down from human resources departments, difference becomes a core driver of business results and a competitive edge for the organization. The End of Diversity as We Know It is particularly insightful for leaders seeking to understand diversity in a new way and implement programs that transform their organizational culture.

Heppner, Rebekah S. The Lost Leaders: How Corporate America Loses Women Leaders. New York: Palgrave Macmillan, 2013. ISBN: 9781137356123.

Much has been written about the "push" factors leading women to leave organizations before reaching the top: from toxic, male-dominated workplace cultures to a lack of sponsors to harmful stereotypes of women as leaders. This book covers those push factors, but does so in a new way, letting women tell their stories in their own words. Heppner's ethnographic approach captures the experiences of ten women leaders, all of whom were highly successful in their organizations but left just before reaching their full potential. The book is organized in themes, covering each push factor and the examples from women who have experienced them. This storytelling format is engaging and accessible for anyone looking for an overview of gender dynamics in American workplaces.

Herring, Cedric, and Loren Henderson. Diversity in Organizations: A Critical Examination. New York: Routledge, 2014. ISBN: 9780415742511.

Diversity in Organizations is written primarily for professionals seeking to establish or develop diversity programs and initiatives in their workplaces. The authors present the business case for diversity-that is, that a diverse workforce has real, measurable benefits for the bottom line and makes a business more competitive than its peers. The book covers diversity's impact on financial performance, productivity, and talent management, as well as best practices in managing diversity initiatives.

Karsten, Margaret Foegen, ed. Gender, Race, and Ethnicity in the Workplace: Issues and Challenges for Today's Organizations. Westport, CT: Praeger, 2006. ISBN: 9780275988029.

This three-volume set is a broad overview of the challenges facing women and ethnic/racial minorities, the causes of workplace inequality, and the strategies for organizations and individuals to achieve equality and inclusion. Volume 1: Management, Gender, and Ethnicity in the United States gives an overall cause-and-effect picture of workplace inequality, using both theoretical and empirical, statistics-based analyses (though the statistics are somewhat outdated). Volume 2: Legal, Psychological, and Power Issues Affecting Women and Minorities in Business focuses on affirmative action, discrimination, stereotypes, sexual harassment, and other issues affecting the legal, social, and psychological treatment of employees based on gender, race, and ethnicity. Volume 3: Organizational Practices and Individual Strategies for Women and Minorities lays out strategies for combating discrimination, from interpersonal communication techniques to formal diversity programs. Authors from business and academia provide contributions to these volumes, lending its value to audiences in both areas.

Liswood, Laura A. The Loudest Duck: Moving beyond Diversity While Embracing Differences to Achieve Success at Work. Hoboken, NJ: Wiley, 2009. ISBN: 9780470485842.

Why do organizational approaches to diversity often fail to deliver their intended results? Laura A. Liswood's The Loudest Duck answers this question in a very approachable style, full of theoretical knowledge, anecdotes, and practical solutions. 
Liswood is the secretary general of the Council of Women Leaders and a nationally recognized speaker on topics relating to diversity and leadership. "The loudest duck gets shot" is a popular Chinese saying, which contrasts to the American line "the squeaky wheel gets the grease." According to Liswood, understanding another's viewpoint and cultural norms is essential in creating a more effective, inclusive workplace.

Mor-Barak, Michàlle E. Managing Diversity: Toward a Globally Inclusive Workplace, 4th edition. Thousand Oaks, CA: SAGE Publications, 2017. ISBN: 9781483386126.

A recipient of numerous awards-including CHOICE Magazine's Outstanding Academic Title and the Academy of Management's George R. Terry Book Award for "outstanding contribution to the advancement of management knowledge"- this volume is a thorough resource on global diversity management for both practitioners and academic researchers. Mor-Barak frames inclusion as the key to driving effective diversity management across organizations, and she covers diversity management not just in terms of corporate programs but also through the lens of international laws, policies, education, and economics. This most recent edition includes updated statistics, legislation, and research, as well as two new chapters: one on inclusive leadership and one on actionable steps for creating inclusive workplaces.

Sandberg, Sheryl. Lean In: Women, Work, and the Will to Lead. New York: Knopf, 2013. ISBN: 9780385349949.

Sheryl Sandberg's book Lean In topped the New York Times and Amazon best-seller lists upon its release in 2013. Sandberg, the chief operating officer of Facebook and one of Fortune's Most Powerful Women of 2017, weaves together powerful research on the gender gap in business leadership with her personal experiences with gender bias throughout her career. The depth of research in this book makes it an especially essential and engaging read for those new to the topic. Sandberg encourages businesses to change the culture regarding gender and leadership, and for women to "lean in" at work. The nonprofit organization LeanIn.org was launched as an extension of the advice given in this book, and its annual "Women in the Workplace" study reports on the representation and barriers faced by women in corporate America.

Thomas, Kecia M. Diversity Dynamics in the Workplace. Belmont, CA: Wadsworth, 2005. ISBN: 9780155069206.

Kecia M. Thomas's book is a concise introduction to workplace diversity, particularly in its explanation of the topic under the umbrella of organizational psychology research and its social, psychological, historical, and legal context in American workplaces today. Thomas organizes the book by key theme: recruitment and attraction; diversity and public policy; socialization; career development; the impact of diversity on group dynamics and outcomes; conflict, justice, and privilege; workplace stressors; developing multicultural leaders; and diversity orientations for organizations and individuals. Some of the statistics included in the book are slightly outdated due to the publication date (2005), but the coverage of major topics, historical landmarks, and major organizations relating to workplace diversity make this a vital resource for readers looking for an introduction to this topic.

Williams, Joan C., and Rachel Dempsey. What Works for Women at Work: Four Patterns Working Women Need to Know. New York: New York University Press, 2018. ISBN: 9781479835454, hardcover; 9781479814312, paperback.

Like Lean In, this book blends research on the current climate for women in the workforce with practical advice on how to navigate it. Joan C. Williams (professor at the University of California, Hastings College of Law and the founding director of the Center for WorkLife Law) teams up with her daughter Rachel Dempsey to reveal insights from their work as well as findings from 127 interviews with women across various demographics and occupations. The authors use anecdotal evidence from the interviews to suggest strategies for professional women, while acknowledging that each approach is not applicable for all women. Originally published in 2014, the 2018 edition offers a new preface written by Williams, and a workbook is available for a separate purchase.

\section{SCHOLARLY JOURNALS}

Gender in Management: An International Journal. Bingley, UK: Emerald Insight, 1985-. Eight times/yr. ISSN: 1754-2413.

Gender in Management: An International Journal is a peerreviewed publication that releases research, practices, and current trends in the broad field of gender in leadership and management. The journal covers many topics, including management and leadership styles, sexual harassment, discrimination, stereotypes, legal issues, and work-life balance. It is indexed in several proprietary databases, including Scopus and Studies on Women Abstracts.

Gender, Work, and Organization. Keele, UK: Wiley-Blackwell, 1994-. Bi-monthly. ISSN: 0968-6673, 1468-0432.

Gender, Work, and Organization, established in 1994, was the first academic journal dedicated to research on the analysis of gender and organizations. A peer-reviewed publication, new issues are released on a bimonthly basis. In addition to core research papers (either theory-driven or empirical in scope), the journal also produces book reviews for emerging books to its central topic. An open-access option is available for authors. Gender, Work, and Organization is indexed in several major proprietary databases, including ABI/INFORM Collection, Gender Studies Collection, ProQuest Central, and PsycINFO/Psychological Abstracts.

Journal of Organizational Behavior. Oxford, UK: Wiley-Blackwell, 1980-. Eight times/yr. ISSN: 0894-3796, 1099-1379.

The Journal of Organizational Behavior is a peer-reviewed scholarly journal published by Wiley-Blackwell eight times 


\section{THE ALERT COLLECTOR}

a year. The journal offers research on all aspects of organizational behavior, including the topics of diversity, equal opportunity, organizational culture and climate, absenteeism and turnover, and work-life balance. The publisher offers an open-access option for authors. The Journal of Organizational Behavior is indexed in several major proprietary databases, including ABI/INFORM Collection, ProQuest Central, and PsycINFO/Psychological Abstracts.

\section{MAGAZINES}

DiversityInc (http://www.diversityinc.com/)

DiversityInc is a popular online publication, providing news and articles on issues relating to corporate diversity. The DiversityInc Top 50 Companies for Diversity list ranks corporations based on performance in four areas: talent pipeline, talent development, leadership accountability, and supplier diversity. Visitors can browse profiles on each company in the top fifty and read about their diversity practices and rankings on more specific DiversityInc lists. While this website is free for access, DiversityInc also maintains a separate subscription-based website.

Profiles in Diversity Journal (http://www.diversityjournal.com/) Profiles in Diversity Journal is a magazine highlighting leaders and best practices in advancing diversity and inclusion across corporate, nonprofit, government, military, and higher education sectors. Previously published on a monthly basis, the magazine now releases new issues three to four times per year (for each season). Feature articles cover major news on inclusive workplaces and the various dimensions of diversity (for example, women, veterans, LGBT). The magazine produces profiles and lists of major CEOs and minority leaders across organizations. Three awards are announced each year: Innovations, Diversity Leader, and Women Worth Watching. The website lists offerings for print subscription.

\section{ORGANIZATIONS}

\section{0-first (https://20-first.com/)}

While primarily a consulting organization, 20-first also provides research and strategies for building genderbalanced businesses. Under the "thinking" heading on the website, viewers can find a list of books, reports, articles, and videos. 20-first also produces a Global Gender Balance Scorecard series, examining the gender balance of executive committees in top companies, separated out by country and industry.

American Association of University Women (https://www. aauw.org/)

Founded in 1881, the American Association of University Women (AAUW) aims to advance "equity for women and girls through advocacy, education, philanthropy, and research." Of particular interest are AAUW's research materials, including a report on the gender pay gap (updated twice each year), barriers and biases faced by women in leadership, women's participation in STEM fields, sexual harassment, and more. AAUW members enjoy access to leadership trainings and salary negotiation workshops.

\section{Catalyst (http://www.catalyst.org/)}

Founded in 1962, Catalyst is a global nonprofit organization that partners with companies to "help build workplaces that work for women." Catalyst offers research, practical solutions, and tools to its network of more than eight hundred Catalyst Supporter organizations. The organization's research reports, covering many aspects of women and workplace inclusion, are available for free on its website. Some material, including webinars and tools, are only accessible for Catalyst Supporter companies. Catalyst's Information Center (winner of the 2011 Special Libraries Association's Centers of Excellence Award) provides several essential products, including statistical fact sheets on topics relating to women and work ("Quick Takes"), infographics displaying the representation of women in various US industries ("Pyramids"), and a collection of resources offering career-related support ("My Career Toolkit").

Diversity Best Practices (https://www.diversitybestpractices $. \mathrm{com} /$ )

Diversity Best Practices is a forum for leaders to share best practices and leading-edge solutions for developing inclusive workplace cultures. Website visitors can browse research based on topic: examples include metrics and assessment, unconscious bias, communications, and sponsorship/ mentorship. The organization offers excellent primers covering all aspects of diversity program management-Diversity Primer (2009), Global Diversity Primer (2015), and HR Executive Diversity Primer (2016) — but these are only available to corporate members.

Employer Assistance and Resource Network on Disability Inclusion (http://www.askearn.org)

The Employer Assistance and Resource Network on Disability Inclusion (EARN) offers tools and resources to assist employers in building inclusive workplaces for employees with disabilities. From the EARN website, visitors can access free webinars, toolkits (organized by type of employer), a workforce recruitment program, and a list of resources for job seekers. The website also offers straightforward information on many topics relating to disability inclusion, such as recruitment and hiring, retention and advancement, laws and regulation, and accessibility. EARN's e-newsletter keeps readers up-to-date on all of the latest news and emerging best practices in this area. 
Human Rights Campaign (http://www.hrc.org/explore/topic /workplace)

Human Rights Campaign is a national civil rights advocacy group for the LGBT community in the United States. The organization's list of workplace resources includes the Corporate Equality Index, a report benchmarking LGBT-related policies and practices across corporations; the webinar series "Forward: What's New in LGBT Workplace Inclusion"; and a guide for collecting data on gender, gender identity, and sexual orientation.

The Society for Human Resource Management (https:// shrm.org)

The Society for Human Resource Management (SHRM) is the world's largest professional organization in the human resources field, providing an enormous amount of resources on all aspects relating to HR. The SHRM website offers many resources relating to workplace diversity and inclusion, though some may be available only to subscribers. The "Introduction to the Human Resources Discipline of Diversity" toolkit is a good place to start, as it gives an overview of the topic and links to additional, more specific SHRM tools throughout the text.

White Men as Full Diversity Partners (https://wmfdp.com/)

Diversity conversations often exclude the group with the most power and leverage to change organizational cultures: white men. The founders of White Men as Full Diversity Partners (WMFDP) recognized this and established a nonprofit organization to bring white men into the dialogue. The organization offers learning labs and summits to address racism, sexism, and homophobia in workplaces. The most popular is the White Men's Caucus, a retreat for white men that confronts the "white male culture" that drives unconscious bias and exclusion in the workplace. The WMFDP website provides information about these learning programs, as well as a list of articles, research studies, and videos on engaging men in diversity initiatives.

\section{References}

1. Bureau of Labor Statistics, "Table 3.5: Civilian Labor Force, Entrants and Leavers, 2006, 2016, and Projected 2026 (Numbers in Thousands)," Employment Projections (2017), https:// www.bls.gov/emp/ep_table_305.htm.

2. Bureau of Labor Statistics, "Projections Overview and Highlights, 2016-26," Monthly Labor Review (2017), https://www .bls.gov/opub/mlr/2017/article/projections-overview-and-high lights-2016-26.htm.

3. United States Equal Employment Opportunity Commission, "Title VII of the Civil Rights Act of 1964," https://www.eeoc.gov /laws/statutes/titlevii.cfm.

4. Bureau of Labor Statistics, "Table 3: Employment Status of the Civilian Noninstitutional Population by Age, Sex, and Race," Current Population Survey, Household Data Annual Averages 2017 (2018), http://www.bls.gov/cps/cpsaat03.htm.

5. Alliance for Board Diversity and Deloitte, "Missing Pieces Report: The 2016 Board Diversity Census of Women and Minorities on Fortune 500 Boards" (February 6, 2017), http://www.catalyst .org/knowledge/missing-pieces-report-2016-board-diversity -census-women-and-minorities-fortune-500-boards.

6. Ibid.

7. American Library Association, "Key Action Areas," 2018, http:// www.ala.org/aboutala/missionpriorities/keyactionareas.

8. American Library Association, Association of College and Research Libraries, "Diversity Standards: Cultural Competency for Academic Libraries," 2012, http://www.ala.org/acrl/stan dards/diversity. 